Arq. Bras. Med. Vet. Zootec., v.67, n.2, p.447-454, 2015

\title{
Avaliação da técnica de coloração AgNOR em testículos de ovinos
}

\author{
[Evaluation of the AgNOR staining method in ovine testicles] \\ M.G.M. Chacur ${ }^{1}$, D.B. Ibrahim², T.A.H. Arrebola ${ }^{2}$, O.C. Sanches ${ }^{1}$, \\ R. Giuffrida ${ }^{1}$, E. $O b a^{3}$, A.A. $\operatorname{Ramos}^{3}$ \\ ${ }^{1}$ Universidade do Oeste Paulista - FCA-UNOESTE - Presidente Prudente, SP \\ ${ }^{2}$ Aluno de pós-graduação - Universidade do Oeste Paulista - UNOESTE - Presidente Prudente, SP \\ ${ }^{4}$ Universidade Estadual Paulista - UNESP-FMVZ - Botucatu, SP
}

\begin{abstract}
RESUMO
A coloração pela prata das regiões organizadoras de nucléolos (NORs) é caracterizada por marcar proteínas ligadas ao ácido ribonucleico ribossômico, avaliando a proliferação em células normais ou neoplásicas. Objetivou-se estudar, em testículos de ovinos obtidos em matadouro, a validade do uso da técnica de coloração pela prata (AgNOR) na identificação das regiões organizadoras de nucléolo (NORs) em células saudáveis da linhagem espermatogênica. Utilizaram-se 43 pares de testículos de ovinos mestiços entre seis e 10 meses de idade. Testes de Wilcoxon e Spearman foram empregados, com nível de 5\%. As médias das NORs nas células das gônadas direita e esquerda foram, respectivamente: espermatogônia $(8,77 \pm 1,14$ e 9,04 $\pm 0,96)$, espermatócitos $(4,99 \pm 2,00$ e $6,20 \pm 2,07 ; \mathrm{P}<0,05)$, Leydig $(8,05 \pm 2,82$ e $7,89 \pm 2,29)$ e Sertoli $(8,07 \pm 1,88$ e $7,61 \pm 2,16 ; \mathrm{P}<0,05)$. Houve correlação $(\mathrm{P}<0,05)$ entre os lados para o número de NORs: espermatócitos x Leydig $(0,49)$; espermatócitos x Sertoli $(0,49)$ e Leydig x Sertoli $(0,96)$. Conclui-se ser válido o emprego da técnica AgNOR para avaliar o potencial proliferativo das células saudáveis em testículos de ovinos com prática execução e baixo custo.
\end{abstract}

Palavras-chave: Ovis aries, testículo, proliferação celular, NOR, abatedouro

\begin{abstract}
The silver staining technique for AgNOR nucleolar organizer regions (NORs) is characterized by marking proteins linked to the ribosomal ribonucleic acid, evaluating cell proliferation. The aim was to study the validity of the AgNOR staining technique in the testicular cell proliferation in crossbred ovine. Forty-three pairs of ovine testicles between 6 and 10 months old were collected. Wilcoxon and Spearman tests were used with a significance level of 5\%. The mean NORs count in cells of the right and left gonads were respectively: spermatogonia $(8.77 \pm 1.14$ and $9.04 \pm 0.96)$, spermatocytes $(4.99 \pm 2.00$ and $6.20 \pm 2.07$, $P<0.05)$, Leydig (8.05 \pm 2.82 and $7.89 \pm 2.29)$ and Sertoli cells $(8.07 \pm 1.88$ and $7.61 \pm 2.16 ; P<0.05)$. There was a correlation between the mean values for the right and left sides for the number of NORs $(P<0.05)$ between Leydig $x$ spermatocytes (0.49); spermatocytes $x$ Sertoli (0.49) and Sertoli $x$ Leydig (0.96). The study demonstrates that the AgNOR staining technique is indicated to evaluate the cell proliferative potential in ovine testis with practical implementation and low cost.
\end{abstract}

Keywords: Ovis aries, testicle, celular proliferation, NOR, slaughterhouse

\section{INTRODUÇÃO}

Contabilizou-se, em 2008, um rebanho de 453.261 cabeças de ovinos no Estado de São Paulo, dentro de 16.628.571 no Brasil, em comparação com o ano de 2000, em que se

Recebido em 25 de março de 2013

Aceito em 30 de julho de 2014

E-mail: chacur@unoeste.br registrou um total de 233.681 nesse estado e de 14.784.958 no país, mostrando uma crescente expansão da ovinocultura paulista (Anuário..., 2010).

A fisiopatologia da reprodução animal aplicada à área da clínica vem ampliando o interesse no 
estudo da proliferação celular, com emprego de técnicas de coloração para fins de estimar o prognóstico e tratamento para as afecções do aparelho reprodutor (Madewell, 2001). A coloração das proteínas argirofílicas, presentes nos cromossomos no estádio de interfase, relacionadas às regiões organizadoras de nucléolo (NORs), pode ser obtida pela técnica denominada de AgNOR, usada em preparações citológicas ou histológicas para a obtenção da taxa de proliferação celular (Crocker et al., 1989; Lindner, 1993) em que, em células normais, as NORs são usualmente organizadas de forma clara em número igual ou maior a um, restritas ao nucléolo, e, em células neoplásicas, as NORs se desagregam do nucléolo e tendem a se dispersar pelo núcleo (Ofner e Schmid, 1996).

Estudos recentes enfocam o uso da técnica de coloração AgNOR em diversas áreas da ciência, como genética e biologia evolutiva de animais da fauna brasileira, segundo Laguna et al. (2010) e Ventua et al. (2014), na espécie canina em processos tumorais, relatados por Santos et al. (2011) e degenerativos, conforme Gonçalves et al. (2008), e na avaliação do metabolismo epitelial em pesquisa odontológica em humanos (Cavalli et al., 2014). Em equinos, a caracterização da atividade da proliferação celular em linfócitos foi verificada por meio da técnica de AgNOR no estudo da alteração na metilação do DNA em processos tumorais (Wnuk et al., 2014).

A técnica de coloração histológica pela prata, denominada de AgNOR, na área da reprodução animal, foi relatada e indicada para a mensuração da proliferação celular em seminoma canino, em que um maior número de NORs está presente em neoplasias metastáticas em relação às não metastáticas (de Vico et al., 1994b). No tumor venéreo transmissível, a técnica colabora com a terapêutica, em que o elevado número de NORs está relacionado com a pobre resposta frente à quimioterapia (Harmelin et al., 1995). Para o carcinoma das células escamosas em cães, o escore das NORs distingue os tumores benignos dos malignos (de Vico et al., 1994a).

O presente estudo justifica-se, pois vale salientar que há escassez de informações, na literatura, relacionadas ao emprego da técnica de coloração AgNOR com enfoque na proliferação celular das estruturas testiculares saudáveis na espécie ovina. Dessa forma, traz informações adicionais e colabora na avaliação andrológica na espécie ovina. Objetivou-se estudar em testículos de ovinos obtidos em matadouro a validade do uso da técnica de coloração pela prata (AgNOR) na identificação das regiões organizadoras de nucléolo (NORs) em células saudáveis da linhagem espermatogênica.

\section{MATERIAL E MÉTODOS}

Um total de 43 pares de testículos de ovinos mestiços, com idade entre seis e 10 meses, foram coletados em abatedouro pertencente ao município de Promissão, São Paulo, Brasil (altitude: 426m, latitude: $21^{\circ} 32^{\prime} 12^{\prime \prime S}$, longitude: 4951'29"O), no período de março a maio, correspondendo, para o hemisfério Sul, ao final do verão e parte do outono. As gônadas foram identificadas quanto ao lado, em testículo direito (TD) e esquerdo (TE), embaladas aos pares, armazenadas e transportadas em solução salina a $25^{\circ} \mathrm{C}$ para o posterior processamento histológico.

Os fragmentos dos testículos medindo $0,5 \mathrm{~cm}$ de espessura foram imersos na solução fixadora de Davidson, composta por: $20 \mathrm{~mL}$ de formol, $30 \mathrm{~mL}$ de álcool 95\%, 10mL de ácido acético e 30mL de água destilada, por 24 a 48 horas e em seguida lavados em água corrente por 1 hora e transferidos para solução de álcool $70 \%$, sendo desidratados em série alcoólica crescente (álcool $80 \%, 96 \%$ e $100 \%$ ), permanecendo 40 minutos em cada um deles. Foi realizada a diafanização (clareamento), utilizando quatro banhos de 40 minutos, sendo o primeiro no álcool + xilol (1:1) e os outros três banhos em xilol. Procedeu-se ao processamento para microscopia óptica para inclusão das amostras em parafina montando os blocos, cortados com $5 \mu \mathrm{m}$ de espessura (Micrótomo rotativo, mod. 820, American Optical N-45387, USA), em que se procedeu à retirada de três cortes: o primeiro para corar com a técnica de hematoxilina - eosina (HE), o segundo para a técnica da AgNOR e o terceiro ficando de reserva. Posteriormente, foram desparafinizadas em xilol por 5 minutos (por três vezes), hidratadas passando lentamente em álcool absoluto por três vezes e lavadas com água por 5 minutos. Os cortes, em lâmina, ficaram incubados ao abrigo de luz em câmara úmida durante 40 minutos a $60^{\circ} \mathrm{C}$, em solução de nitrato de prata, obtida utilizando-se $1 \mathrm{~g}$ de gelatina incolor, $0,5 \mathrm{~mL}$ de ácido fórmico e $50 \mathrm{~mL}$ 
de água deionizada (solução A) e $12,5 \mathrm{~g}$ de nitrato de prata e $25 \mathrm{~mL}$ de água deionizada (solução B), sendo uma parte de solução A para duas partes de solução B (1 sol. A: 2 sol. B), conforme Ploton (1986), modificada por Sanches (2010).

As amostras foram retiradas da solução corante quando apresentaram coloração marrom-escura e lavadas em água deionizada morna a $45^{\circ} \mathrm{C}$ para retirar o precipitado formado pela gelatina. Após esse procedimento, as lâminas passaram em solução de tiossulfato de sódio a $5 \%$ durante 5 minutos para retirar a prata reduzida depositada sobre as células. As amostras foram desidratadas (álcool 96\% e 100\% - três vezes, lentamente; xilol - três vezes, lentamente), os cortes foram contracorados em Van Gieson ("verde luz") por $3 \mathrm{~min}$; em seguida, os cortes foram montados com lamínula e resina sintética (Entellan®, Merck KGaA, Darmstadt, Alemanha).

A contagem das NORs foi realizada observando os pontos de coloração negra no interior dos nucléolos em cada um dos tipos celulares: espermatogônias, espermatócitos, espermátides e nas células de Leydig e Sertoli, por meio de microscopia óptica na magnitude de (1000x).

O padrão de contagem das NORs foi realizado considerando-se 10 células/campo de cada tipo celular, repetindo-se em 10 campos microscópicos aleatórios, totalizando a contagem em 100 células de cada um dos tipos celulares, conforme Sanches (2010).

Para cada testículo avaliado, foi calculada a média aritmética do número de regiões organizadoras de nucléolo (NORs) em relação aos 100 campos avaliados, individualmente, para cada tipo celular. Sequencialmente, os conjuntos de valores obtidos no procedimento anterior foram testados pelo método de KolmogovSmirnov para avaliar a normalidade dos dados. Nesse procedimento, apenas a variável "contagem média de NORs/campo para as células de Leydig do testículo direito" foi considerada como paramétrica $(\mathrm{P}<0,10)$. Por essa razão, optou-se pelo uso de testes não paramétricos para efetuar as comparações estatísticas (Pagano e Gauvreau, 2004).
A comparação entre as contagens do número de NORs observadas nos testículos direito e esquerdo foi realizada mediante o teste não paramétrico dos postos de Wilcoxon. A correlação existente entre o número das NORs observadas para os quatro tipos celulares estudados foi avaliada pelo cálculo do coeficiente de correlação não paramétrico de Spearman, com estimativas por ponto e por intervalo com $95 \%$ de confiança, separadamente para os testículos direito e esquerdo. Os coeficientes de Spearman calculados foram testados estatisticamente para a hipótese de que diferem significativamente do valor zero. Para detectar a presença de valores influentes "outliers", recorreu-se à avaliação gráfica por meio da construção de gráfico do tipo "Boxplot". As análises foram realizadas utilizando-se o pacote computacional Bioestat segundo Ayres et al. (2007) com nível de significância de 5\%.

O projeto de pesquisa foi aprovado junto ao Comitê de Ética em Pesquisa - CEP da UNOESTE.

\section{RESULTADOS}

A análise microscópica dos testículos revelou integridade do arcabouço e desenvolvimento do epitélio germinativo dos túbulos seminíferos, o qual apresentou entre cinco e seis camadas de células, somando os compartimentos: basal e adluminal (Fig.1).

A histologia testicular pela técnica de coloração com uso da prata está representada na (Fig.2), onde se visualizam as regiões organizadoras de nucléolo (NORs) em forma de grânulos escuros, distribuídos no núcleo das células do epitélio espermatogênico sadio, os quais puderam ser identificados, individualizados e contados perante a microscopia óptica.

Na Tabela 1, estão descritos as médias e desvios padrão das contagens de NORs/campo e respectivos desvios padrões observados para os tipos celulares para o testículo direto e esquerdo. Na Tabela 2, estão descritas as análises de correlação entre as médias das NORs, agrupando-se os tipos celulares dois a dois, individualmente para cada testículo. 


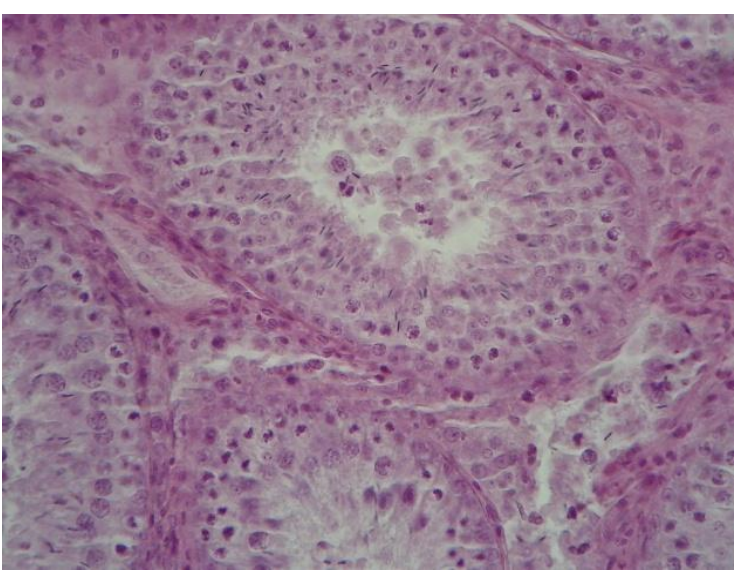

Figura 1. Testículo de carneiro: técnica de coloração (HE), túbulos seminíferos e epitélio germinativo íntegros, presença de espermatozoides na luz tubular, magnitude (400x).

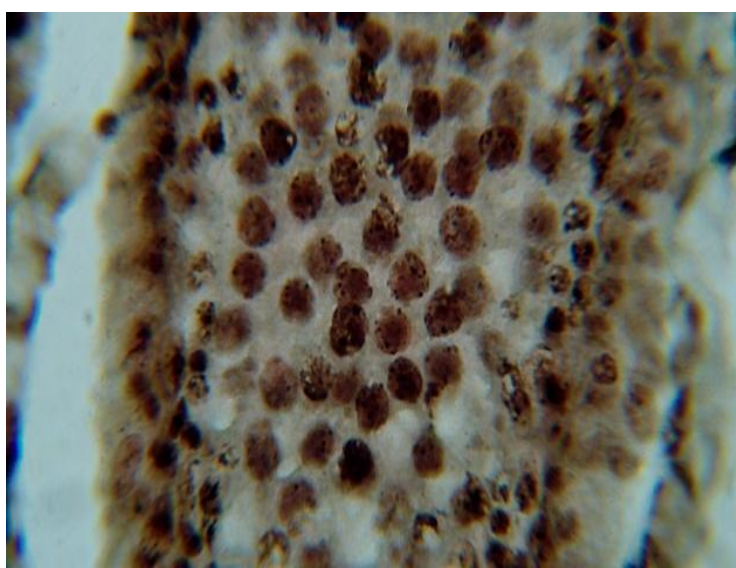

Figura 2. Testículo de carneiro: técnica de coloração pela prata (AgNOR), epitélio germinativo íntegro. Os pontos negros nos núcleos são as regiões organizadoras de nucléolo (NORs), magnitude (1000x).

Tabela 1. Média e desvio padrão do número de regiões organizadoras de nucléolo (NORs) no núcleo dos diferentes tipos de células de testículos esquerdo (TE) e direto (TD) em ovinos mestiços

\begin{tabular}{lcccc}
\hline Variável & TE $(\mathrm{n}=43)$ & $\mathrm{TD}(\mathrm{n}=43)$ & $\begin{array}{c}\text { Soma dos postos de } \\
\text { Wilcoxon }\end{array}$ & $\mathrm{P}$ \\
\hline Espermatogônia & $9,04 \pm 0,96$ & $8,77 \pm 1,14$ & 90 & 0,5904 \\
Espermatócito & $6,20 \pm 2,07$ & $4,99 \pm 2,00$ & 790 & $<0,0001^{*}$ \\
Células de Leydig & $7,89 \pm 2,29$ & $8,05 \pm 2,82$ & -182 & 0,2744 \\
Células de Sertoli & $7,61 \pm 2,16$ & $8,07 \pm 1,88$ & -428 & $0,0098^{*}$ \\
\hline
\end{tabular}

\section{$* \mathrm{P}<0,05$.}

Tabela 2. Coeficientes de correlação de Spearman (R) para as regiões organizadoras de nucléolo (NORs) no núcleo das células de testículos esquerdo (TE) e direito (TD) estimados por ponto e intervalo com $95 \%$ de confiança (IC95\%) em ovinos mestiços

\begin{tabular}{lcccccc}
\multicolumn{1}{c}{ variável } & \multicolumn{3}{c}{ TE $(\mathrm{n}=43)$} & \multicolumn{3}{c}{ TD $(\mathrm{n}=43)$} \\
\cline { 2 - 7 } & $\mathrm{R}$ & $\mathrm{IC} 95 \%$ & $\mathrm{P}$ & $\mathrm{R}$ & $\mathrm{IC} 95 \%$ & $\mathrm{P}$ \\
\hline Espermatogônia x & $-0,446$ & $-0,664 /-0,160$ & $0,0027^{*}$ & $-0,282$ & $-0,543 / 0,0286$ & 0,0663 \\
Espermatócitos & $-0,680$ & $-0,817 /-0,471$ & $<0,0001^{*}$ & 0,258 & $-0,0550 / 0,525$ & 0,0948 \\
Espermatogônia x Leydig & $-0,593$ & $-0,762 /-0,348$ & $<0,0001^{*}$ & 0,605 & $0,364 / 0,770$ & $<0,0001^{*}$ \\
Espermatogônia x Sertoli & 0,645 & $0,421 / 0,795$ & $<0,0001^{*}$ & 0,326 & $0,0201 / 0,577$ & $0,0324^{*}$ \\
Espermatócitos x Leydig & 0,586 & $0,339 / 0,758$ & $<0,0001^{*}$ & $-0,0677$ & $-0,368 / 0,246$ & 0,6658 \\
Espermatócitos x Sertoli & 0,922 & $0,858 / 0,958$ & $<0,0001^{*}$ & 0,834 & $0,708 / 0,909$ & $<0,0001^{*}$ \\
Leydig x Sertoli & & & & & &
\end{tabular}
$* \mathrm{P}<0,05$.

$\mathrm{Na}$ Figura 3, podem ser observadas as representações gráficas do tipo "Box-plot" separadamente para o número de NORs para cada tipo celular, cada população celular, segundo o testículo avaliado. Foram classificadas, como valores influentes "outliers", duas observações referentes ao testículo esquerdo dentro da população celular de espermatogônias e uma observação para a população celular de espermatócitos do testículo direito. A remoção desses valores não influenciou significativamente os resultados estatísticos observados e por essa razão optou-se por mantê-los na análise. 


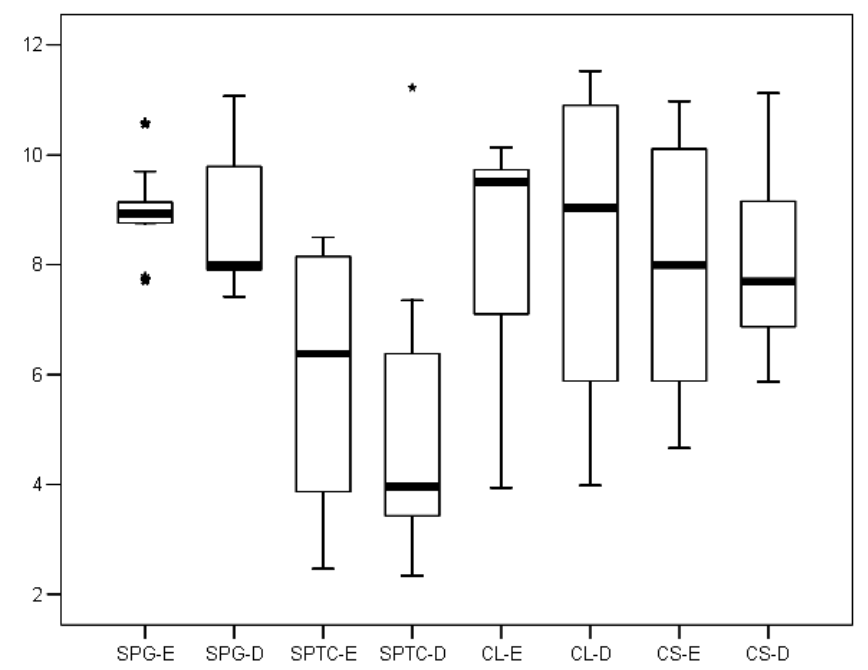

Figura 3. Comparação das contagens do número de regiões organizadoras de nucléolo (NORs) no núcleo das células de testículos esquerdo (E) e direito (D) dos tipos celulares: espermatogônias (SPG-E e SPGD), espermatócitos (SPCT-E e SPCT-D), células de Leydig (CL-E, CL-D) e células de Sertoli (CS-E e CL-D). As linhas no interior dos boxes denotam o segundo quartil (50\% dos dados - mediana), as linhas superiores, o terceiro quartil ( $75 \%$ dos dados) e as inferiores, o primeiro quartil (25\% dos dados). As linhas aplicadas indicam os limites dos valores extremos, e os pontos externos a elas indicam os "outliers".

\section{DISCUSSÃO}

Vale destacar que, na presente discussão, optouse por comparações quanto à utilidade da técnica de coloração pela prata (AgNOR) em distintas espécies animais, incluindo o ser humano, devido à escassez de informações na literatura relativas à proliferação celular pelo emprego dessa técnica, diretamente relacionada com o aparelho reprodutor masculino. A utilização da coloração pela prata com a técnica de AgNOR se mostra atual e de importante valia em estudos de proliferação celular em distintas áreas, como a da odontologia humana na avaliação histológica de tecidos íntegros ou perante processo inflamatório (Cavalli et al., 2014). Na veterinária, a contagem de NORs foi utilizada em estudos da proliferação celular em cães portadores de doenças articulares degenerativas, por Gonçalves et al. (2008), e de tumor venéreo transmissível, segundo Santos et al. (2011), como um dos indicados parâmetros para nortear a continuidade dos tratamentos. Para a genética e biologia evolutiva, a técnica de AgNOR é usada em estudos do cariótipo com enfoque em regiões específicas dos cromossomos, como os telômeros, servindo como marcador filogenético (Laguna et al., 2010; Ventura et al., 2014). Existe uma relação diretamente proporcional entre o ganho de faixa etária com a elevação da metilação do DNA em linfócitos de equinos, deixando esses animais mais susceptíveis aos processos tumorais (Wnuk et al., 2014).

Dessa forma, perante a observação microscópica do material corado pela técnica de $\mathrm{HE}$, revelou-se a integridade histológica dos túbulos seminíferos (Fig. 1), assegurando a representatividade do material processado e analisado para fins de estudar a viabilidade e utilidade da técnica de coloração AgNOR para o epitélio germinativo testicular íntegro. Relato esse, da integridade histológica pela HE, similar ao descrito por Castrillejo et al. (1995) como representativo em estudos de espermatogênese em ovinos da raça Corriedale a partir de seis meses de idade, criados extensivamente no Uruguai, indicando que nessa faixa etária os ovinos podem ser utilizados para estudos nessa linha. A integridade histológica dos túbulos seminíferos e a boa qualidade do sêmen estão presentes no processo de proliferação em células saudáveis da linhagem espermatogênica (Chacur, 2012; Chacur et al., 2012).

No presente trabalho, tratando-se de animais mestiços e jovens, o desenvolvimento histológico testicular foi adequado. Outro ponto diz respeito 
à qualidade do material processado, a qual se mostrou adequada para a visualização e contagem do número de regiões organizadoras de nucléolo (NORs), nos distintos tipos celulares avaliados, corroborando Müller et al. (1994) e Ohyama et al. (1995), que recomendaram a técnica de coloração, em humanos, para o diagnóstico do carcinoma testicular, devido à facilidade e rapidez na execução da mesma, aliada à qualidade quanto à coloração do material que pode ser fixado em formalina e emblocado em parafina, além do baixo custo agregado para a realização da técnica. Xu et al. (1997) complementaram esse raciocínio, ao descrever que a coloração oferece um indicador adicional para o prognóstico de tumores no testículo em seres humanos.

Nos cortes histológicos, o número de NORs contadas nos tipos celulares avaliados: espermatogônia, espermatócitos, células de Leydig e de Sertoli, apresentou uma distribuição homogênea nos campos microscópicos, concordando com os achados de Holstein e Lauke (1996) em humanos para testículos saudáveis, e que, na ocorrência de células tumorais, as mesmas se concentram em regiões focais dos túbulos seminíferos.

Houve diferença significativa para as médias do número de NORs entre os lados direito e esquerdo para espermatócitos e células de Sertoli (Tab. 1). Sugere-se, para fins de comparação das taxas de proliferação celular, realizar contagens das NORs para os distintos tipos celulares em ambas as gônadas. A taxa de proliferação celular pode oscilar em relação à gônada contralateral, de forma independente para o mesmo tipo celular em questão. Essa diferença observada entre os lados pode estar relacionada com a individualidade metabólica de cada gônada, bem como pelo efeito compensatório entre elas para fins de manutenção das células da linhagem espermatogênica para a produção de gametas.

Em humanos com carcinoma testicular, o número médio de NORs/núcleo foi de 26,86 $\pm 2,68$ para as células tumorais, mas inferior nas células sadias, sendo nas espermatogônias $8,18 \pm 2,20$ e nas células de Sertoli 12,96 $\pm 2,44$ (Müller et al., 1994). A despeito da grande diferença filogenética entre ovinos e humanos, no presente estudo com ovinos machos, a média de NORs/núcleo foi similar para as espermatogônias, porém inferior para as células de Sertoli, quando comparadas às células também sadias do estudo supracitado de Müller et al. (1994).

As correlações significativas entre espermatócito $\mathrm{x}$ células de Leydig, espermatócito $\mathrm{x}$ células de Sertoli e entre as de Leydig e Sertoli (Tab. 2) podem ser explicadas pelo conceito da "regulação local" (Ergün et al., 1994) entre os túbulos seminíferos e o tecido intersticial, pois segmentos dos túbulos vizinhos são supridos por vasos sanguíneos em comum. Seguindo esse conceito, as células de um túbulo podem influenciar as de outros túbulos adjacentes por meio de um microambiente em comum, modulados por fatores de crescimento.

Perante as informações acima descritas, recomenda-se a validade do uso da técnica de coloração pela prata (AgNOR) para avaliar a proliferação de células testiculares sadias e não apenas em processos tumorais, como mostrou Pich et al. (2000) em revisão de literatura sobre o aparelho reprodutor humano, em que, quanto maior o número de NORs, maior a atividade proliferativa das células.

Em virtude de a técnica de AgNOR, relacionada ao estudo da proliferação celular de testículos saudáveis nos animais domésticos e em especial nos ovinos, não trazer informações na literatura consultada, recomenda-se que novos estudos sejam realizados para fins de somatória de resultados com o uso da técnica de coloração e contagem de NORs utilizada. Vale salientar que o presente resultado e as informações relatadas no respectivo estudo podem servir como base para futuros procedimentos e análises da atividade espermatogênica na espécie ovina em exames de citologia testicular.

Devido à realização simultânea das colorações com hematoxilina-eosina e AgNOR nos fragmentos testiculares, cujas leituras microscópicas revelaram túbulos seminíferos íntegros, sugere-se a adoção do número de NORs contadas nos distintos tipos de células da linhagem espermatogênica como indicativo de tecido normal; podendo tais valores colaborar no diagnóstico de patologias do testículo. 


\section{CONCLUSÕES}

O estudo em questão demonstra que a técnica de coloração histológica pela prata (AgNOR) é indicada para a avaliação do potencial proliferativo das células testiculares saudáveis em ovinos. A coloração AgNOR revelou qualidade na identificação e individualização das regiões organizadoras de nucléolo (NORs), propiciando a contagem numérica das mesmas nos diferentes tipos celulares analisados. Estiveram presentes a vantagem quanto ao uso da técnica devido à praticidade de execução e o baixo custo econômico.

\section{AGRADECIMENTOS}

Ao Conselho Nacional de Desenvolvimento Científico e Tecnológico (CNPq), à UNOESTE e à UNESP pelas bolsas concedidas e pelo apoio logístico e financeiro.

\section{REFERÊNCIAS}

ANUÁRIO da Pecuária Brasileira, v.1, 273p., 2010.

AYRES, M.; AYRES JÚNIOR, M.; AYRES, D.L.; SANTOS, A.A. (Ed.). BIOESTAT Aplicações estatísticas nas áreas das ciências biomédicas. Brasil: ONG MAMIRAUA, 2007, 49p.

CASTRILlEJO, A.; MORANÃ, A.; BIELL, A. et al. Onset of spermatogenesis in Corriedale ram lambs under extensive rearing conditions in Uruguay. Act. Vet. Scand., v.38, p.161-173, 1995.

CAVALLI, D.; MODOLO, F.; RIVERO, E.R.C. Avaliação do metabolismo epitelial em cistos radiculares pela técnica de AgNORS. Rev. Odontol., v.43, p.77-81, 2014.

CHACUR, M.G.M. Seminal Plasma Proteins as Potential Markers of Relative Fertility in Zebu Bulls (Bos taurus indicus) Chapter XX. In: IN TECH (Ed.). Electrophoresis. Croatia: RIJEKA, 2012. p.1-20.

CHACUR, M.G.M.; MIZUSAKI, K.T.; SANTOS, F.H. et al. Influence of year season on semen characteristics and hormonal levels in Nelore and Simental bulls. Arq. Bras. Med. Vet. Zootec., v.64, p.540-546, 2012.
CROCKER, J.; BOLDY, D.A.R.; EGAN, M.J. How should we count AgNORs? Proposals for a standardized approach. J. Pathol., v.158, p.185188, 1989.

De VICO, G.; AGRINI, U.; MAIOLINO, P. Nucleolar size and mitotic índex in basal cell carcinoma (BCC) and squamous cell carcinoma (SCC) of canine skin. J. Vet. Med. Res., v.41, p.76-79, 1994a.

De VICO, G.; PAPPARELLA, S.; Di GUARDO, $\mathrm{G}$. Number and size of silver-stained nucleoli (AgNOR clusters) in canine seminomas: correlatio with histological features and tumour behavior. J. Comp. Pathol., v.110, p.267-273, 1994b.

ERGÜN, S.; STINGL, J.; HOLSTEIN, A.F. Segmental angioarchicteture of lobules testis in man. Andrologia, v.26, p.143-150, 1994.

GONÇALVES, G.; MELO, E.G.; GOMES, M.G. et al. Effects of chondroitin sulfate and sodium hyaluronate on chondrocytes and extracellular matrix of articular cartilage in dogs with degenerative joint disease. Arq. Bras. Med. Vet. Zootec., v.60, p.93-102, 2008.

HARMELIN, A.; ZUCKERMAN, A.; NYSKA, A. Correlation of AgNOR protein measurements with prognosis in canine transmissible venereal tumour, J. Comp. Pathol., v.112, p.429-433, 1995.

HOLSTEIN, A.F.; LAUKE, H. Histologic diagnostics of early testicular germ-cell tumor. Int J. Urol., v.3, p.165-172, 1996.

LAGUNA, M.M.; AMARO, M.C.; MOTT, T. et al. Karyological study of Amphisbaena ridley (Squamata, Amphisbaenidae), an endemic species of the Archipelago of Fernando de Noronha, Pernambuco, Brazil. Gen. Molec. Biol., v.33, p.57-61, 2010.

LINDNER, L.E. Improvements in the Silverstaining Technique for Nucleolar Organizer Regions (AgNOR). J. Histochem. Cytochem., V.41, p.439-445, 1993.

MADEWELL, B.R. Cellular proliferation in tumors: a review of methods, interpretation, and clinical applications. J. Vet. Intern. Med., v.15, p.334-340, 2001. 
MÜLLER, M.; LAUKE, H.; HARTMANN, M. The value of the AgNOR staining method in identifying carcinoma in situ of the testis. Pathol. Res. Pract., v.190, p.429-435, 1994.

OFNER, D.; SCHMID, K.W. Standardized AgNOR analysis: Its use-fulness in surgical oncology. Histochem. Cell Biol., v.106, p.193196, 1996.

OHYAMA, O.; ITO, A.; TOKUYAMA, S. et al. Clinical significance of proliferating cell nuclear antigen (PCNA) and argyrophilic nucleolar organizer region (AgNOR) in testicular tumors. Japanese J. Urol., v.86, p.1543-1551, 1995.

PAGANO, M.; GAUVREAU, K. (Ed.) Princípios de bioestatística. Brasil: PIONEIRA, 2004, 52p.

PICH, A.; CHIUSA, L.; MARGARIA, E. Prognostic relevance of AgNORS in tumor pathology. Micron., v.31, p.133-141, 2000.

SANCHES, O.C. Quantificação dos mastócitos nas neoplasias mamárias malignas de cadelas: análise histopatológica, histoquímica $e$ imunoistoquímica. 2010. 83f. Tese (Doutorado em Medicina Veterinária) - Faculdade de Medicina Veterinária e Zootecnia, Universidade Estadual Paulista, Botucatu.
SANTOS, F.G.A.; MORO, L.; CASSALI, G.D. et al. Cell proliferation markers in the transplanted canine transmissible venereal tumor. Arq. Bras. Med. Vet. Zootec., v.63, p.1345-1352, 2011.

VENTURA, K.; MOREIRA, C.N.; MORETTI, R. et al. The lowest diploid number in Testudines: Banding patterns, telomeric and 45S rDNA FISH in Pellocephalus durelimianus, $2 \mathrm{n}=26$ and $\mathrm{FN}=52$ (Pleurodira, Podocnemididae). Gen. Molec. Biol., v.37, p.61-63, 2014.

WNUK, M.; LEWINSKA, A.; GURGUL, A. et al. Changes in DNA methylation patterns and repetitive sequences in blood lymphocytes of aged horses. $A G E$, v.36, p.31-48, 2014.

XU, J.; ZHENG, J; QIAN, S. Video image analysis of AgNORs distribution in the testicular tumor. Zhonghua Wai Ke Za Zhi, v.35, p.738741, 1997. 